\title{
Senior And Junior Faculty Perspectives On A Tenure Process In Health Promotion And Education
}

\author{
Liliana Rojas-Guyler and Randall R. Cottrell \\ University of Cincinnati
}

\begin{abstract}
This paper reviews the concept of tenure and its importance in health education. It also illustrates the experiences and perspectives of a senior level tenured professor and a junior level non-tenured assistant professor, from a health education program at a Research I university. The goals of this paper include providing future or beginning junior faculty with: 1) perspectives on tenure and its importance within the health promotion profession, 2) helpful hints for obtaining tenure from the view of a senior tenured faculty member, 3) ways that senior faculty members can support junior faculty in obtaining tenure, and 4) key issues identified by a junior faculty member currently on the tenure track.

(C) 2005 Californian Journal of Health Promotion. All rights reserved.

Keywords: tenure, tenure process, health education, faculty perspective
\end{abstract}

\section{Introduction}

For many health promotion professionals the culmination of their undergraduate and/or master's level professional preparation signals the beginning of their career. Whether they practice health promotion at a community, school, or worksite setting, they will soon be utilizing their skills to assess, plan, implement, and evaluate health promotion programs. Other health promotion graduates, however, choose to become future educators for the profession. In other words, they want to teach university students to become health educators. For most, choosing this route means a terminal degree at the doctorate level and obtaining a tenure track position at a college or university.

Doctoral training is primarily focused on providing students with the competencies needed to conduct research that will further the knowledge base of the profession. In addition, however, those prepared at the doctoral level that will be training future health educators must fully understand the history, philosophy, competencies and foundations of the profession. They must be able to teach and mentor students to become effective health education professionals. The learning initiated during doctoral preparation is integral to the success of the future professor including the ability to obtain tenure. The depth and breadth of learning experiences provided to doctoral students is essential in producing a well-rounded tenuretrack professor who is prepared to succeed. In essence a new $\mathrm{PhD}$ accepting a position at a Research I institution must have the skills to conduct research, effectively teach students and participate in service activities. New faculty members lacking experience or skills in any of these important areas are going to be at a disadvantage in the tenure process.

This paper will review the concept of tenure and its importance. It will also illustrate our experiences and perspectives as a senior level tenured professor and a junior level non-tenured assistant professor, in the Health Promotion and Education Program at the University of Cincinnati. Our views are limited to the environment within this Research I institution (The Carnegie Foundation for the Advancement of Teaching, 2000) and previous institutions we attended or at which we worked. The goals of this paper include providing future or beginning 
junior faculty with: 1) perspectives on tenure and its importance within the health promotion profession, 2) helpful hints for obtaining tenure from the view of a senior tenured faculty member, 3) ways that senior faculty members can support junior faculty in obtaining tenure, and 4) key issues identified by a junior faculty member currently6 on the tenure track.

\section{What Is Tenure And Why Is It Important?}

Tenure is defined by the American Heritage Dictionary as "the status of holding one's position on a permanent basis without periodic contract renewals" (2000). Tenure is the status granted to a faculty member after being deemed worthy of such status by a group of his or her peers. Most institutions have written guidelines outlining the quantity, quality and types of evidence needed to document successful achievement of tenure. Junior faculty members are usually required to apply for tenure in their sixth or seventh year of service (Klausner, et al., 2004; Francis \& Pratto, 1982). Those not receiving tenure usually have one additional year at the institution during which they look for another position. Along the way to tenure, there are usually interim reviews to evaluate candidates for contract renewal or faculty reappointment.

Research, Service and Teaching are commonly assessed at all reviews, whether reappointment or tenure. At Research I institutions all three of these areas are said to be important; however, a prolific record of research and scholarly writing is expected and usually outweighs teaching and service. A minimal level of achievement in teaching and service is also required.

Although the tenure process seems to be nonforgiving and somewhat tenuous, it is an integral part of academic tradition in most American universities. And even though the tenure process has weaknesses such as the often ambiguous nature of the process, focus on research rather than teaching as a disservice to students, and inequality in racial and ethnic characteristics of the tenured body at many institutions (Boyer, 1990; Jackson, 2004; Sorcinelli, 2002) it continues to be the predominantly accepted outcome of evaluation in academia. The very structured tenure process also has its benefits, including consistency and rigor in promoting faculty while weeding out those that do not demonstrate competence or sufficient productivity. Other benefits identified in 1973 by the American Association of University Professors as cited in Francis \& Pratto (2003) are that tenure provides: “1) Freedom of teaching and research and of extramural activities and 2) a sufficient degree of economic security to make the profession attractive to men and women of ability (p. 2).”

The tenure process as illustrated by Stronck (2004) typically includes the following: a committee of departmental/program peers usually conducts the most important part of the review; the chair or head of the applicant's program writes a performance review, college level reviews ensure consistency in the review process and analyses of the applicant's qualifications; and deans, provosts and presidents review to enforce minimum university standards. The long line of checks and balances throughout the process helps to insure fairness and a thorough review of an applicant's scholarship, teaching and service record (Stronck, 2004).

\section{Key Factors Associated With Tenure Success from the Senior Faculty Perspective}

As a senior faculty member, I see the tenure process as being extremely important (much more important than I thought it was as an untenured junior faculty member). The tenure process allows programs the opportunity to observe and evaluate young faculty over an extended period of time before making them a permanent commitment. Once tenure is granted to an individual faculty member that person will likely be part of that faculty until she/he chooses to leave, does something unethical or immoral, or retires. In essence, tenure means that the university and program are making a long-term investment in that faculty member. It is obviously in the best interest of tenured senior faculty and the university to make sure that faculty members receiving tenure are productive and will contribute to the long-term success of the program. 
So what are the characteristics of junior faculty that senior faculty look for? From my perspective junior faculty need to be well rounded. They should demonstrate they have the skills and perseverance to conduct research, write scholarly papers and present to their professional colleagues. These are competencies that are expected at Research I institutions, but they are also the competencies needed to further the reputation of an academic program and university. In other words, junior faculty should contribute to the standing and reputation of the program while in the process of moving toward tenure. In addition, I want junior faculty to be good teachers and good mentors to our students. Teaching does not get as much attention at Research I institutions as research, but I still want my junior faculty colleagues to provide quality instruction and to mentor students in the program. Poor teaching can quickly ruin the on campus reputation of an academic program. Next, I want junior faculty that are willing to provide service to the profession and are willing to extend their talents to the community. This is probably less important than research or teaching, but I really want to see some evidence that a junior faculty member is willing to give to the profession and community. Finally, I want to work with junior faculty who are team players. They should interact well with faculty, staff, students and administration. Nothing can be more disruptive to the work of an academic program than one or more faculty members who are "I" centered instead of team or program centered.

I would readily admit that my expectations and the expectations of most Research I institutions for junior faculty are high. Further, I believe that most junior faculty members being hired directly from their $\mathrm{PhD}$ professional training programs need assistance to meet these expectations. I would also contend that senior faculty should take some responsibility for helping junior faculty to succeed in academia. There are a number of ways senior faculty can provide this assistance.

First, senior faculty members need to be clear when communicating promotion and tenure criteria to junior faculty. While it may not be possible, for example, to say exactly how many publications are needed for tenure, at least give some ranges. Let junior faculty know how many publications previous faculty had who were successful in the tenure process. Ambiguity surrounding the tenure process can be extremely stressful and unproductive for junior faculty. Senior faculty should provide their perceptions of how research, teaching, advising and community service are evaluated and considered in relation to tenure at their given institutions. Second, fully describe the entire process one goes through to obtain tenure at a given institution. From my experience the process can differ greatly from institution to institution and it should not be kept a secret. What is the timeline and who reviews what materials. Let junior faculty see portfolios of successful candidates so they will know what types of documentation they need to maintain. Third, push junior faculty to get started quickly on research. New junior faculty cannot spend all of their time on teaching the first year even though teaching several new courses is going to take a lot of effort. At most institutions junior faculty members have only five years to demonstrate their research competence, as they will be submitting their tenure folios in year six. Waiting until year two to begin one's research is not advisable. Fourth, encourage junior faculty to consider how they might utilize their teaching and service to generate research projects. For example, if a junior faculty member volunteers time with a community agency and can utilize that work as the source of a research project it makes for an extremely efficient use of time and can be a major asset to the community agency as well. At the same time senior faculty need to council junior faculty not to get too involved in community work at the expense of their research agenda. Community work can be fun and personally rewarding, but it can also consume inordinate amounts of time. Fifth, senior faculty can collaborate with junior faculty on new or ongoing research projects. Encouraging junior faculty to assist with the ongoing work of a senior faculty member can often provide junior faculty with valuable learning experiences, and one or more quick publications that can help reduce some of the tenure pressure. In addition senior faculty can many times lay the 
groundwork for junior faculty to become involved in collaborative research with other faculty, students, and professionals in the field. Junior faculty need to be working on several research projects simultaneously and should not put all of their eggs in one research basket.

In summary, obtaining tenure is certainly a demanding and stressful process. Non-tenured faculty must work extremely hard throughout the first years of their academic career to prove their ability to research, publish, teach and serve. Senior faculty members have a responsibility to their programs and universities to make sure that they only recommend competent, productive and collegial junior faculty for tenure. The senior faculty also, however, has the responsibility and privilege to mentor junior faculty to be successful in the tenure process.

\section{Setting Yourself up for Success: A Junior} Faculty Member's Thoughts and Experiences As far back as I can remember I wanted to teach. I remember seating at the head of my family's dinner table with all my dolls perfectly aligned and listening to me teach. It is a passion that is still very much a part of my life today as an assistant professor at the University of Cincinnati. I truly enjoy my students as well as my research and service responsibilities. I am in the third year of my first tenure tract academic appointment having just graduated in August of 2002. I remember the day I came for my interview at UC like it was yesterday. I remember later accepting the position, but most vividly I remember my first meeting with our Division Head when she gave me the Reappointment, Promotion, and Tenure Policies document for our division. At that point it really hit home that I was going to have to produce to maintain my position on the faculty. If I was to successfully attain tenure, the Reappointment, Promotion, and Tenure Policies document was going to be extremely important.

I am now almost three years into the process and am counting each month and year, as I cannot afford to waste time. Six years seems like a long time, but it goes quickly. Careful planning will not only ensure that I have met the expectations, but that I do so in a timely manner. My division head reviews me, like other junior faculty, once a year to ensure appropriate progress and a mutual understanding of expectations. During my second year, I had to submit a reappointment portfolio. Reappointments are granted if the candidate has successfully met committee and university expectations of growth and development in the areas of research, teaching and service. At this point a faculty member can be given a one, two or three year reappointment or can be released from service. I was granted a two rear reappointment meaning that I will have another reappointment review during my fourth year of service and prior to submitting my promotion and tenure portfolio in year six. If granted promotion to Associate Professor with tenure at that time, I can then work toward becoming a Full Professor. Associate Professors usually wait at least six or more years before seeking promotion to Full Professor.

My success in attaining reappointment for two more years, and the optimism my mentors and I share that I am positioned to succeed in achieving sustained and progressive performance, are based on thoughtful planning and collaborative work. I do not claim to have all the answers, nor do I claim for these to be proven strategies. I am merely sharing the techniques that I have found to be useful in navigating through the tenure expectations. I do have to say that, much of what I believe to be essential in a junior faculty member's ability to be a prolific researcher and accomplished teacher, rests on their professional academic preparation at the doctorate level. For this reason, I will shortly digress to a point I introduced in the first paragraph of this paper.

The choices made when completing the doctorate, that is, what program students choose to attend and choice of experiences while in the program, will greatly influence the ease they have in transitioning into a tenure tract position. If a student wants to be a tenure tract faculty member, choosing an institution that provides significant research skills, particularly practical experiences in addition to research methods and statistical courses, is in my opinion indispensable. Graduating with not only textbook knowledge but also practical 
experiences in designing, conducting and writing research is essential. Focusing on teaching provides excellent background for the future professor, but doing so without seeking research experience can cause one to be unprepared to do research.

Seldom is one's dissertation sufficient to establish sound research skills; though, using $\mathrm{PhD}$ training to establish a research agenda is very important. This is especially true given the fact that one is expected to publish several articles by the second year review, and it takes an average of two years to bring a research idea from conception to publication (Cornelius, Moore \& Gray, 1997). One must be well prepared to produce publications as early as the first year. This means that having doctorate level research articles ready to be written or already in press is not just beneficial but almost a necessity. Also, selecting a dissertation topic that can be of sufficient significance for publication in the first year would be very valuable. In addition to obtaining practical research experience at the doctoral level, developing networks and working relationships with other students or faculty researchers can provide additional avenues to conduct and publish research.

So, once September 1, 2002, came around, I was ready and eager to start my new academic appointment. It was important to me, and a priority encouraged by my mentors, to balance my time wisely. It would have been easy to get lost in developing the six new courses I was assigned, with little attention to my research agenda. I would caution new faculty to ensure that they save or assign days of the week that are dedicated solely to writing and other research endeavors. As the second year approached, I found it useful to make sure that I had one project in each stage. That is, one project in the planning phase (seeking funding, human subjects protection review, etc), one in the data collection stage, one undergoing data analysis, one being written, one under review for publication, and ideally one in press. While this may sound like a lot of projects at one time, and it is, remember not all projects yield publishable results. Some may be suspended, delayed, or not receive funding. Having more than one project active at a time ensures more possibilities of success.

In addition to having multiple projects in different stages, it is also a good idea to plan and design research projects that provide multiple opportunities for publication. That is, collecting different sets of data with the same study. Whenever possible plan a study that could have the potential to produce two or more publications. For example, writing a paper on the survey design and pilot testing of a new instrument and then writing a paper on the study results using the survey with the planned target population. The same can be said for professional presentations and professional service. Whenever possible, provide community and professional service that can lead to research and publication in your area of expertise. Community work can also provide access to a desired population for your studies.

Another factor involved in the review process and thus affecting when and how many publications need to be produced is the institutions' promotion/tenure deadline. That is, the deadline by which the different levels of review must see the applicant's materials. In my case, reappointment was to be granted effective September of 2005. My complete portfolio and all accompanying materials were due to the program level committee in February of 2004. So in reality I had seventeen months from when I was hired to produce a portfolio representative of my ability to fulfill expectations for reappointment. In other words, I had to submit my materials in my second year even though I had a three-year appointment. This is typical in many universities. Usually, the institution wants an applicant to be notified of their reappointment status with one year remaining in their contract. In case the candidate is not recommended for reappointment/tenure/promotion, then he or she has one year to attain alternate employment. Another reason for this aggressive timeline is the time required to move the candidate's portfolio through several levels of review.

Networking and being brave enough to approach other faculty in the program can be very helpful 
in managing and completing simultaneous projects. I remember that in my case, it was intimidating to go up to the senior faculty who had hired me and say I need help. I needed guidance with the institution's grants and other funding opportunities and processes; I needed help with choosing the most appropriate analyses for some data sets; I needed guidance on classroom planning and management; etc. Although I had been "trained" in all these areas, no single set of educational experiences prepared me for the multitude of scenarios I faced as a new faculty member. Seeking advice assertively was hard at first since I did not want to be perceived as ill prepared or incompetent. However, I encountered a lot of support and guidance once I asked. I also learned that other, more experienced, professors also sought out help and often collaborated with colleagues. For example, some still refer to their statistics and research methods textbooks from graduate school. So I would add that, at the junior faculty level, it is normal to feel hesitant and inexperienced with some aspects of being a professor. And that attaining proficiency in all aspects of academia is a dynamic and long-term process. Taking advantage of institutional or informal mentoring support can significantly enhance the junior faculty experience and outcome.

It is also important to network and communicate with other faculty members who have recently gone through the tenure process. They often have very valuable advice and specific information on preparing for tenure review. These mentoring relationships, whether with your supervisors or other colleagues, can also help shed light on the unwritten aspects of the tenure process. It was mentioned earlier that written guidelines usually exist for tenure and promotion processes at individual institutions. However, these tend to be general and sometimes subjective in nature. Oftentimes the use of words and phases such as "outstanding performance" or "significant achievement" do not necessarily offer enough guidance. These words do not tell a junior faculty member the number of publications; number of committees; minimum mean score for teaching evaluations; etc. These are the unwritten rules. And although mentors can only tell you what they have seen as an average in their experience, it is better than having no idea at all and falling short of the mark.

It is also important to note that even though I have generally received cohesive advise from different senior faculty, on occasion there have been differences of opinion among mentors. Thus it is important to sometimes get a third opinion or to make the best informed decision based on their advice combined with your own experience and perspective.

\section{Summary}

Experiences attained at the doctorate level can be crucial in helping establish a sound research agenda and can support early career research efforts and outcomes. Balancing teaching, service and research is integral to success as a tenure tract junior faculty. Whenever possible service should also contribute to research efforts. It is also my experience that having several projects at different stages helps ensure productivity and timeliness in the rigorous tenure process. Being aware of an institution's expectations and guidelines, as well as obtaining mentorship on the unwritten expectations can provide a well-rounded picture of the process. Additionally, establishing networks of colleagues not only for advice but also to produce publishable studies can result in increased productivity.

Working as a college professor is an enjoyable, flexible, personally rewarding, prestigious and demanding career. Tenure is an important aspect of academia. For those considering a career in academia, we suggest you carefully select your doctoral program. Be sure that it is going to provide you with plenty of research and teaching experience. Ask if you will have at least two to three publications by the time you graduate. For those who are currently in tenure track positions, carefully consider our experience-based hints, recommendations and guidance as provided in this article. Remember, however, that our experience is limited to the six institutions where we have worked and studied and primarily taken from our current institution. Be sure to carefully examine the promotion and tenure requirements 
at your own institutions and conduct a reality check on our hints, recommendations and guidance with faculty and administrators at your institution.

\title{
References
}

Boyer, E. L. (1990). Scholarship reconsidered: Priorities of the professorate. Princeton, NJ: The Carnegie Foundation for the Advancement of Teaching.

Cornelius, L. J., Moore, S. E., Gray, M. (1997). The ABCs of tenure: What all African American faculty should know. The Western Journal of Black Studies, 21(3), 150-155.

Francis, R. G., \& Pratto, D. J. (1982). The tenure process and you. The American Sociologist, 17(Aug), 140-143.

Jackson, J. (2004). The story is not in the numbers: Academic socialization and diversifying the faculty. NWSA Journal, 16(1), p. 172-186. EBSCO Host Database. Retrieved February 8, 2005, from http://search.epnet.com/login.aspx?direct=true\&db=aph\&an=13006896

Klausner, et al. (2004). Report of the faculty senate ad hoc joint committee on tenure. University of Florida. Retrieved February 8, 2005, from http://www.senate.ufl.edu/minut_agen/tenureReport.pdf

Pickett, J. P. et al. (Eds.). (2000). The American heritage ${ }^{\circledR}$ dictionary of the English language (4th ed.). Boston: Houghton Mifflin.

Sorcinelli, M. D. (2002). New conceptions of scholarship for a new generation of faculty members. New direction for teaching \& learning, Summer(90), pp. 41-49. EBSCO Host Database. Retrieved February 8, 2005, from http://search.epnet.com/login.aspx?direct=true\&db=aph\&an=9175142

Stronck, D. R. (2004). A helpful tenure process. Phi Kappa Phi Forum, 84(4), 28-29.

The Carnagie Foundation for the Advancement of Teaching. (2000). The 2000 Carnegie classification: Background and description (excerpt). Retrieved November 18, 2004, from http://www.carnegiefoundation.org/Classification/CIHE2000/background.htm

\author{
Author Information \\ Liliana Rojas-Guyler, PhD, CHES* \\ Assistant Professor \\ University of Cincinnati \\ Health Promotion and Education Program \\ PO Box 210002 \\ Cincinnati, OH 45221-0002 \\ E-Mail: Liliana.Guyler@uc.edu \\ Randall R. Cottrell, PhD, CHES \\ Professor \\ University of Cincinnati \\ Health Promotion and Education Program \\ PO Box 210002 \\ Cincinnati, OH 45221-0002 \\ * corresponding author
}

